\title{
Community-Acquired Methicillin-Resistant Staphylococcus aureus Severe Infection in Two Healthy Patients with Ear Piercing
}

\author{
Emilce de los Ángeles Méndez ${ }^{1^{*}}$, María Sol Garberi ${ }^{1}$, María Rosa Baroni ${ }^{1,3}$, María Alejandra Mendosa ${ }^{1,2}$, \\ Glenda Segovia $^{1}$, Sabrina Analí Cristobal ${ }^{1,2}$, Analía Susana Mollerach ${ }^{2}$, Alicia Adela Nagel ${ }^{2}$, Gabriela De \\ Giovanni $^{3}$
}

${ }^{1}$ Faculty of Biochemistry and Biological Sciences, National University of Litoral, Argentina; ${ }^{2} J o s e$ María Cullen Hospital-Santa Fe, Argentina; ${ }^{3}$ Alassia Hospital-Santa Fe, Argentina

\begin{abstract}
Body piercing is a type of self-expression which is based on creating a hole in the skin, subcutaneous tissue or cartilage in order to be able to insert jewellery. The aim was to report severe CA-MRSA infections in two patients, one adult and one child, from different teaching hospitals, in the same period of time and both of them had penetrating implantation as a risk factor. The two isolates were CA-MRSA PVL (+), spa t019, cassette IV and ST30. Referring to the clonal relationship, PFGE showed that both isolates were closely related, indicating that they were probably part of the outbreak. It was not possible to investigate if the piercing setter was the same person in both cases.
\end{abstract}

Keywords: CA-MRSA; Body piercing; Molecular characterization

\section{INTRODUCTION}

Body piercing is a type of self-expression which is based on creating a hole in the skin, subcutaneous tissue or cartilage in order to be able to insert jewellery; it can also be defined as a factor that causes alteration of local homeostasis and exposure to communicable diseases [1-3]. Now-a-days, piercing has steadily become more popular, particularly among young people as a means of being different [2]. Piercing that is performed under unhygienic conditions, however, can cause certain complications for days, weeks or months after implantation [2,3]. Studies have demonstrated the occurrence of nerve injuries, allergic reactions, cutaneous infections, edema, granuloma, hematoma, bleeding, skin abscess and contact dermatitis [1-4]. Infection severity ranges from local infections (e.g., impetigo and cellulitis) to more extensive or even systemic infections such as osteomyelitis, toxic shock syndrome, bacteremia, Hepatitis B, C and D, human immunodeficiency virus (HIV), syphilis and tetanus [1-3].

Staphylococcus aureus is a human opportunistic pathogen, and methicillin-resistant $S$. aureus (MRSA) causes a wide variety of infections worldwide, including hospital-associated MRSA (HAMRSA) and community-associated MRSA (CA-MRSA) infections $[5,6]$. The last ones have the ability to infect people living in a community without personal or associated risk factors, suggesting enhanced bacterial virulence [5-7]. It's a gram positive coccus that can spread from the skin to the lungs, the bloodstream or other body organs, being able to cause primary skin and soft tissue infections, mainly furunculosis and abscesses, but can also cause necrotizing tissue infections and fulminant pneumonia [8-13].

MRSA typing is used to support infection control measures. While pulsed-field gel electrophoresis (PFGE) is a "gold standard" for strain typing of MRSA, DNA sequence-based approaches are becoming more frequently used because sequence data can easily be transferred between laboratories via the Internet [14]. Multi-locus sequence typing (MLST) provides global epidemiology data and it can be used mainly to identify clonal relationship [6,15]. Single-locus DNA sequencing of repeat regions of the spa gene (protein A) is especially interesting for rapid typing of MRSA in a hospital setting. There is a good correlation between clonal groupings determined by MLST and the respective spa types [14]. Furthermore, most CA-MRSA isolates harbor the virulence factor Panton-Valentine leucocidin

${ }^{*}$ Correspondence to: Emilce de los Ángeles Mendez, Faculty of Biochemistry and Biological Sciences, National University of Litoral, Argentina, Tel: 54342156129933; E-mail: emendez@fbcb.unl.edu.ar

Received: April 01, 2019; Accepted: April 15, 2019; Published: April 23, 2019

Citation: Mendez EA, Garberi MS, Baroni MR, Mendosa MA, Segovia G, Cristobal SA, et al. (2019) Community-Acquired Methicillin-Resistant Staphylococcus aureus Severe Infection in Two Healthy Patients with Ear Piercing. J Bacteriol Parasitol. 10:356. doi: 10.4172/2155-9597.1000356

Copyright: ( 2019 Méndez EA, et al. This is an open-access article distributed under the terms of the Creative Commons Attribution License, which permits unrestricted use, distribution, and reproduction in any medium, provided the original author and source are credited. 
(PVL) and the mecA gene which is carried in the staphylococcal cassette chromosome mec (SCCmec) type IV or V [11]. The aim was to report two cases of severe CA-MRSA infections in patients from different teaching hospitals, in the same period of time and both of them had piercing implantation as a risk factor.

\section{CASE REPORTS}

On October 11, 2016, a 17-year-old woman was admitted to an adult hospital with symptoms that led to suspicion of meningitis and sepsis. The patient had no risk factors associated with hospital infection, or previous MRSA colonization/infection but she had an ear piercing. She was not a drug addict, neither had history of skin disease nor other illness. Because of her medical condition she was transferred to the Intensive Care Unit (ICU) where blood cultures were requested. She was empirically treated with vancomycin plus clindamycin. Once the patient stabilized, a cerebrospinal fluid (CSF) sample was also taken. MRSA (MRSA-1) was recovered from both blood and CSF. On the fourth day, the antibiotic treatment was switched to vancomycin plus daptomycin. Because of a periorbital cellulitis appearance, daptomycin was replaced by linezolid. After both samples were negativize, the patient continued with daptomycin, linezolid and rifampin. A week later, the patient was discharged.

In the same city, on the same day, a previously healthy 14-yearold boy with an ear piercing, was admitted to a children's hospital. He had a painful hip and fever that made him nearly impossible to walk. Due to the clinical observations, he was transferred to the hospital temporary care room where several studies were carried out, including a hip ultrasound, which showed fluid collection in the left femoral coxus joint. Urine, blood and joint fluid cultures were requested. MRSA (MRSA-2) was recovered from blood and joint fluid but not urine. Because of the patient's condition continued to worsen, he was transferred to the Intensive Care Unit (ICU) where he was intubated and ventilated. He developed septic shock secondary to MRSA arthritis. Considering the culture results, antibiotic therapy was intravenous vancomycin plus clindamycin. After two days, the patient continued hemodynamically unstable, presenting refractory hypotension, and high doses of inotropes were required. In addition, he developed refractory hypoxemia caused by necrotizing pneumonia. On the 3rd day of hospitalization, the patient became agitated and suffered a cardiac arrest. He underwent cardiorespiratory resuscitation for over $45 \mathrm{~min}$, but unfortunately died.

\section{Bacteriological studies}

Biological specimens were cultured using standard methods: The identification and the antibiotic susceptibility were performed by different automatized systems in adult and children's hospitals, Phoenix (BD Phoenix ${ }^{\mathrm{TM}}$ ) and Vitek 2C System, respectively. Both isolates were methicillin resistant Staphylococcus aureus.

MRSA-1 and MRSA-2 showed identical antibiotic susceptibility profile and the same MIC value to vancomycin; they were categorized as susceptible to erythromycin, ciprofloxacin, gentamicin, rifampin and linezolid. Daptomycin was tested by epsilometric method.

Molecular characterization: Polymerase chain reaction (PCR) was used to detect the presence of the Panton-Valentine leucocidin and the SCCmec and spa type $[14,16,17]$. MLST was performed to detect sequence type (ST) [15]. Both spa and ST were sequenced in Korea (Macrogen).

In both isolates, detection of pul gene was positive and the spa type t019. MRSA-1 and MRSA-2, harbored the SCCmec type IV and the ST was ST30. The clonal relationship determined by pulsed field gel electrophoresis (PFGE) using SmaI enzyme for genomic DNA digestion showed that both isolates were closely related, indicating that they were probably part of the outbreak [18].

\section{DISCUSSION AND CONCLSUION}

These results confirmed the genetic relationship between both isolates of CA-MRSA, and the important fact of belonging to the same clonal complex.

According to Egea et al. which reported that in Argentina, most CA-MRSA belonged to two major clones: ST30-SCCmecIVct019-PVL+ and ST5-IV-SCCmecIVa-t311-PVL+, our isolates were defined as ST30 by MLST typing. In accordance with Balci et al. the practice of piercing is steadily becoming more widespread in Western societies. Studies have indicated differing prevalence rates from $26 \%$ up to $60 \%$; in Argentina there are few papers that communicate piercing infection prevalence. These authors also express that the parts most commonly showed piercing is ear cartilage as the two patients presented in this report.

Due to adult patient's reluctance and boy's death it was not possible to investigate if the piercing setter was the same person in both cases. The clinical impact of this report was that two isolations, from different hospitals of the same city were molecular characterized as ST30, spa t019, PVL (+), cassette IV. We conclude that in both cases, the epidemiological investigation showed none of the patients had any risk factors, other than, piercing implantation. Therefore, we assume it could be the starting point for CA-MRSA infection.

\section{ACKNOWLEDGMENT}

This work was partly supported by research grants from the Universidad Nacional del Litoral, Santa Fe, Argentina (CAI+D 2016).

\section{REFERENCES}

1. Battagin G, Sarmati L, Sordillo P, Picchi G, Calisti G, Laura C, et al. Complication of nasal piercing by Staphylococcus aureus endocarditis: A case report and a review of literature. Cases Journal. 2010;3:37-40.

2. Balci S, Sari E, Mutlu B. Comparison of risk-taking behaviour and frequency of piercing and tattooing among university students. JPak Med Assoc. 2015;65(6):587-592.

3. Purim KSM, Rosario BA, Rosario CS, Guimarães ATB. Piercings in medical students and their effects on the skin. An Bras Dermatol. 2014;89(6):905-910. 
4. Owonikoko KM, Tijani AM, Bajowa OG, Atanda OO. Use of safety pin on garments in pregnancy: A belief and cultural practice with potential harmful effect. AIMS Public Health. 2017;4(1): $19-32$.

5. Chen Z, Han C, Huang X, Liu Y, Guo D, Ye X. A molecular epidemiological study of methicillin-resistant and methicillinsusceptible Staphylococcus aureus contamination in the airport environment. Infect Drug Resist 2018;11:2363-2375.

6. Dittmann KK, Chaul LT, Lee SHI, Corassin CH, Fernandes De Oliveira CA, Pereira De Martinis EC, et al. (2017) Staphylococcus aureus in Some Brazilian Dairy Industries: Changes of Contamination and Diversity. Front Microbiol 2017;8:2049-2061.

7. Egea AL, Gagetti P, Lamberghini R, Faccone D, Lucero C, Vindel A, et al. (2014) New patterns of methicillin- resistant Staphylococcus aureus (MRSA) clones, community-associated MRSA genotypes behave like healthcare-associated MRSA genotypes within hospitals, Argentina. Int J Med Microbiol 2014;304(8):1086-1099.

8. Ensinck G, Ernst A, Lazarte G, Romagnoli A, Sguassero Y, Míguez $\mathrm{N}$, et al. Community-acquired methicillin-resistant Staphylococcus aureus infections: A 10-years' experience in a children's hospital in the city of Rosario, Argentina. Arch Argent Pediatr 2018;116(2): 119-125.

9. Vire FP, Akpaka PE, Unakal C. Molecular characterization of methicillin-resistant Staphylococcus aureus isolates from rural community settings in Trinidad and Tobago. Niger J Clin Pract 2018;21(12):1596-1601.

10. Vazquez NM, Guido CP, Fiorilli G, Moreno S. Emerging mupirocin resistance in methicillin-resistant Staphylococcus aureus isolates at a tertiary care children's hospital in Argentina. Arch Argent Pediatr 2019;117(1):48-52.

11. Méndez EA, Roldán ML, Baroni MR, Mendosa MA, Cristóbal SA, Virgolini SM, et al. A case of familial transmission of community-acquired methicillin-resistant Staphylococcus aureus carrying the $\ln u(\mathrm{~A})$ gene in Santa Fe city, Argentina. Rev Argent Microbiol. 2012;44(4):303-305.

12. Ding YL, Fu J, Chen J, Mo SF, Xu S, Lin N, et al. Molecular characterization and antimicrobial susceptibility of Staphylococcus aureus isolated from children with acute otitis media in Liuzhou, China. BMC Pediatrics. 2018;18(1):388-395.

13. Méndez EA, Baroni MR, Mendosa MA, Segovia G, Bellon A, Mollerach AS, et al. Staphylococcus aureus: An unusual resistance mechanism?. J Bacteriol Parasitol. 2015;6:1-2.

14. Harmsen D, Claus H, Witte W, Rothgänger J, Claus H, Turnwald $\mathrm{D}$, et al. Typing of methicillin-resistant Staphylococcus aureus in a university hospital setting by using novel software for spa repeat determination and database management. J Clin Microbiol. 2003;41(12):5442-5448

15. Enright MC, Day NP, Davies CE, Peacock SJ, Spratt BG. Multilocus sequence typing for characterization of methicillinresistant and methicillin-susceptible clones of Staphylococcus aureus. J Clin Microbiol. 2000;38(3):1008-1015.

16. Lina $G$, Piemont $Y$, Godail-Gamot F, Bes M, Peter MO, Gauduchon V, et al. Involvement of Panton-Valentine leukocidinproducing Staphylococcus aureus in primary skin infections and pneumonia. Clin Infect Dis. 1999;29(5):1128-1132.

17. Oliveira DC, De Lencastre H. Multiplex PCR strategy for rapid identification of structural types and variants of the mec element in methicillin-resistant isolates of Staphylococcus aureus. Antimicrob Agents Chemother 2002;46(7):2155-2161.

18. Tenover FC, Arbeit RD, Goering RV, Mickelsen PA, Murray BE, Persing $\mathrm{DH}$, et al. Interpreting chromosomal DNA restriction patterns produced by pulsed-field gel electrophoresis: criteria for bacterial strain typing. J Clin Microbiol 1995;33(9):2233-2239. 